\title{
Article
}

\section{Childhood loneliness as a predictor of adolescent depressive symptoms: an 8- year longitudinal study}

Qualter, Pamela, Brown, Stephen L., Munn, Penny and Rotenberg, Ken J.

Available at http://clok.uclan.ac.uk/1265/

Qualter, Pamela, Brown, Stephen L., Munn, Penny and Rotenberg, Ken J. (2010) Childhood loneliness as a predictor of adolescent depressive symptoms: an 8-year longitudinal study. European Child \& Adolescent Psychiatry, 19 (6). pp. 493-501. ISSN 1018-8827

It is advisable to refer to the publisher's version if you intend to cite from the work. http://dx.doi.org/10.1007/s00787-009-0059-y

For more information about UCLan's research in this area go to http://www.uclan.ac.uk/researchgroups/ and search for < name of research Group>.

For information about Research generally at UCLan please go to http://www.uclan.ac.uk/research/

All outputs in CLoK are protected by Intellectual Property Rights law, including Copyright law. Copyright, IPR and Moral Rights for the works on this site are retained by the individual authors and/or other copyright owners. Terms and conditions for use of this material are defined in the policies page.

\section{CLoK}

Central Lancashire online Knowledge www.clok.uclan.ac.uk

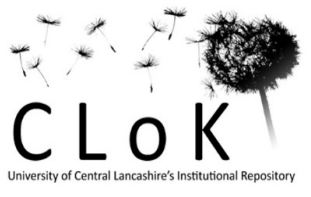




\section{Childhood loneliness as a predictor of adolescent depressive symptoms: An 8 year longitudinal}

study

\section{ARTICLE}

Other: Qualter, P., Brown, S.L., Munn, P., \& Rotenberg, K. (2010). Childhood loneliness as a predictor of depression: An 8 year longitudinal study. European Journal of Child and Adolescent Psychiatry, 19, 493-501. Print ISSN: 1018-8827; Online ISSN: 1435-165X; doi:10.1007/s00787-009-0059-y Available at:

http://link.springer.com/article/10.1007\%2Fs00787-009-0059-y?LI=true

It is advisable to refer to the publisher's version if you intend to cite from the work. To link to this article http://link.springer.com/article/10.1007\%2Fs00787-009-0059-y?LI=true

\section{Footnotes:}

${ }^{1}$ We use criteria of a comparative fit index (CFI) above .95, and the root mean square error of approximation (RMSEA) less than .10 to indicate adequate model fit as suggested elsewhere [62].

${ }^{2}$ One potential issue in studies of this nature is that an atypical group of high scorers on both loneliness and depression variables may drive the findings of the analysis. This is a particular issue with the interaction variable, which emphasises the effect of consistently high loneliness scores. To investigate whether a very small number of children were lonely at both time points, but were also very depressed at Time 3, we observed the scattergrams comparing T1 loneliness, T2 loneliness, the interaction term, and the predicted values obtained from a multivariate predictive equation composed of these variables, with T3 depression scores. We found no evidence of correlations being overly influenced by high scorers. 
Abstract: Childhood loneliness is characterised by children's perceived dissatisfaction with aspects of their social relationships. This eight year prospective study investigates whether loneliness in childhood predicts depressive symptoms in adolescence, controlling for early childhood indicators of emotional problems and a sociometric measure of peer social preference. 296 children were tested in the infant years of primary school (T1: 5 years of age), in the upper primary school (T2: 9 years of age) and in secondary school (T3: 13 years of age). At T1, children completed the loneliness assessment and sociometric interview. Their teachers completed externalization and internalization rating scales for each child. At T2, children completed a loneliness assessment, a measure of depressive symptoms, and the sociometric interview. At T3, children completed the depressive symptom assessment. An SEM analysis showed that depressive symptoms in early adolescence (age 13) were predicted by reports of depressive symptoms at age 8, which were themselves predicted by internalization in the infant school (5 years). The interactive effect of loneliness at 5 and 9, indicative of prolonged loneliness in childhood, also predicted depressive symptoms at age 13. Parent and peer-related loneliness at age 5 and 9, peer acceptance variables, and duration of parent loneliness did not predict depression. Our results suggest that enduring peer-related loneliness during childhood constitutes an interpersonal stressor that predisposes children to adolescent depressive symptoms. Possible mediators are discussed.

Keywords: loneliness; depression; depressive symptoms; longitudinal study; adolescence; transient loneliness; enduring loneliness; chronic loneliness; stability of loneliness; children. 
Introduction

Adolescent clinical depression has a prevalence rate of between $4 \%$ and $8.3 \%$ [4] and is a risk factor for adult depression [21, 23]. Sub-clinical depression in adolescents may also constitute a risk factor, as adolescents with sub-threshold levels of depression are no different from adolescents diagnosed with depression in terms of their level of adult depression and suicidal ideation [20]. Interpersonal sources of stress influence vulnerability towards adolescent depression. For example, relationship issues such as poor peer and family relationship quality, difficulty being close to peers and difficulty trusting peers predict depressive symptoms over 6 months [19]. Other interpersonal risk factors are perceived lack of peer and family support [34], and perceived negative daily interpersonal experiences or hassles [61].

\section{Peer Acceptance/Rejection, Childhood Loneliness, and Adolescent Depression}

Several researchers $[5,48]$ suggest that interpersonal stress can be a consequence of negative peer experiences (peer rejection) during childhood. Peer acceptance/rejection reflects the collective liking/disliking a group has towards an individual member [9, 40]. Low peer acceptance has consistently been linked to later depressive systems in longitudinal studies [5, 6, 18, 39, 50, 53]. Nevertheless, not all children who experience social rejection show these symptoms, with only $2-5 \%$ of them meeting diagnostic criteria for depression [46].

Research emphasising the primacy of children's perceptions of social rejection [50] shows that actual rejection over time does not predict increased depression, but perceived rejection does [35]. Indeed, the discrepancy between actual and desired social networks appears to better predict later depressive symptoms than peer rejection $[46,53]$.

It seems, then, that a child's perception of whether they have poor social relationships, rather than objective measures of social networks, is important in determining depressive symptoms. Thus, it 
seems likely that loneliness, which is viewed as developing when a discrepancy exists between the interpersonal relationships one wishes to have, and those that one perceives they currently have [52] has a role to play in predicting depression.

Loneliness is unpleasant, is not synonymous with social isolation or rejection, and is the result of perceived quantitative or qualitative deficiencies in one’s social relations [52]. Empirical research shows concurrent links between loneliness and depression in both adult [12, 24, 49] and adolescent samples [37, 41]. Also, prospective investigations amongst older adults (54 yrs+) have found that loneliness predicts subsequent depressive symptoms up to 10 years after initial testing [10, 26, 31]. Thus, it seems reasonable to speculate that childhood loneliness predisposes individuals to depressive symptoms during adolescence.

Both peers and parents are vital sources of social support during childhood and adolescence, and researchers have argued that it is important to examine the influence of both peer- and parent-related loneliness in relation to depressed mood [8]. In cross-sectional work conducted with adolescents, peer related loneliness is more predictive of depressive symptoms than parent related loneliness [41], possibly as peers are the preferred source of support throughout childhood and adolescence [63]. The transience of loneliness is another important consideration. Loneliness can be a transient and/or situational response to experiences such as loss, rejection, or other social disappointments. In itself, this is not pathological $[33,65]$. However, adults who experience loneliness for 2 or more consecutive years display a greater number of behavioural and cognitive deficits related to social skills and interpersonal relations than those whose loneliness is transient [65, 36]. In addition, children whose lonely feelings increased over a one-year period scored low on peer acceptance and friendship at time 2 and became more self-blaming in their attributions [57]. 
Thus, we suggest, that enduring loneliness represents an interpersonal stressor that plays a causal role in the development of later depressive symptoms. Proposed mechanisms by which stable loneliness could predict symptoms of depression include a genetic deficit in the appreciation of relationships, that causes changes in actual social engagement and self appraisal [22], the development of maladaptive cognitive biases and coping strategies that predispose an individual to depression [54,55], and changes in activation and functioning of the HPA axis [11]. We do not test these possible mediators in the current study: instead, we provide the first longitudinal study from childhood to adolescence that investigates whether enduring loneliness is more likely to be associated with pathological processes than transient loneliness, which may merely represent a common developmental experience. Thus, the present research was guided by the notion that enduring loneliness is more likely to predict later depressed feelings than loneliness assessed at only a single time point.

\section{Aims of the study}

There are clear concurrent associations between measures of loneliness and depressive symptoms in adolescents. However, although self perceived loneliness appears to be a better predictor of distress than peer acceptance/rejection, there are no prospective studies of its transition from childhood to adolescence. Thus, it is unknown whether loneliness in early childhood predicts symptoms of depression in adolescence. Also, past research has not differentiated between enduring and nonenduring loneliness, nor measured the relative impact of each. To test the hypothesis that childhood loneliness is linked to adolescent depressive symptoms we used an eight-year prospective design, with 3 data collection points.

The use of a prospective design requires statistical control of participants' Time 1 (T1) and Time 2 (T2) vulnerabilities to depressive symptoms. T1 participants in this study were too young to 
meaningfully complete questionnaire measures of depression [44], so teacher reports of externalising and internalising behavioural problems were used. These have been shown to be precursors to depressive feelings [32, 42]. We have conceptualised loneliness as a subjective representation of the child's social world; their perception of the quantity or quality of their social relationships and accompanying affect [58]. To control the influence of objective peer social interactions, we used sociometric measures of peer acceptance/rejection. Our aim was to see if T1 and T2 peer and parent related loneliness, could predict depression beyond the effects of T1 internalising and externalising behavioural problems, T2 depression, and T1 and T2 peer acceptance/rejection.

We also tested the hypothesis that enduring loneliness represents a risk factor that is independent of the additive effect of loneliness at Times 1 and 2. We computed the product of Time 1 and Time 2 loneliness (high scores indicate greater loneliness at both time points). Compared to an additive model, this multiplicative model emphasises the weighting afforded to higher scorers at both time points. Thus, the interaction term emphasises the effect of consistently scoring highly on loneliness. An independent influence of loneliness duration will be demonstrated by independent prediction of depressive symptoms (T3) for this interaction effect after we have controlled for the effect of T1 and T2 loneliness.

\section{Method}

\section{Design and Procedure}

Data were collected at three time points: T1, T2 T3. At T1, children completed the loneliness assessment, which was individually administered in the child's school by the female principal investigator. The children's teachers completed externalization and internalization rating scales for each child. At T2, children completed the loneliness assessment with the appropriate age-specific administration (a change from using a picture format to text), the depression assessment, and the 
sociometric interview in one-to-one interviews with a research assistant. At T3, children completed the depression assessment.

\section{Participants}

All participants were enrolled in the state education system, were primarily Caucasian, and the researchers had received parental permission for their participation in the study at each time period. The sampling frame was developed to ensure that children were chosen from a group of schools in Lancashire that were reasonably representative and comparable to schools in different areas of the UK as determined by the government Index of Multiple Deprivation (http://www.communities.gov.uk/archived/general-content/communities/indicesofdeprivation). This index combines a number of indicators, chosen to cover a range of economic, social and housing issues, into a single deprivation score for local areas in England, and is commonly used in British educational and health research [2]. Of those primary schools approached, 30 agreed to take part in the study by sending consent forms to parents and providing study space in the school for data collection. The distribution of the final 30 schools on the deprivation indices was representative of the schools who were asked to take part in the study. All children between 58 and 62 months who attended the targeted schools were possible participants. A total of 842 children were therefore selected, of which 640 (76\%) participated in the study at T1. 46\% (296 children: 146 males; 150 females) of the original 640 children participated at all three time points.

Of the 640 children recruited into the study, 400 participated at T2, which took place 4 years later. Of the 240 who did not participate at T2, 182 could not be located, 34 had parents who refused consent for participation at T2, 11 did not complete all questionnaires or declined to participate, and 13 were absent from school on the days of data collection. Compared to children who participated at 
the T2 contact, non-participating children who only took part at T1 were no more likely to be socially rejected by peers, suffer from parent loneliness or peer loneliness or have internalising or externalising problems at T1 (t [639] = .27, 1.26, .78, 1.13, .65 respectively).

Of the 400 recruited to T2, 296 participated at T3, which took place another four years later. Of the 104 who dropped out between T2, 36 could not be located, 3 had parents who refused consent for participation at T2, 7 did not complete all questionnaires or declined themselves to participate, 14 were absent from school on the days of data collection, and 44 had incomplete data-sets. Compared to T1 children who participated at T3, those who dropped out between T1 and T3 showed greater parent-related loneliness at $\mathrm{T} 1(\mathrm{t}[639]=1.66, \mathrm{p}<.001)$. They did not differ from those who participated at T1 on socially preference, peer loneliness or internalization or externalization at T1 (t [639] $=.15, .53,1.16,63$ respectively).

\section{Materials}

Teacher Ratings of Internalisation and Externalization. The T-CARS (Teacher-Classroom Adjustment Rating Scale [15] was administered at T1. It consists of 39 behaviourally oriented items describing school adjustment problems, used by teachers to rate externalising and internalising behaviour. Items from Section One were used. This measure shows good validity [64], and predicts later depression $[16,43]$. Class teachers had all been teaching the participating children for six hours per day for at least six months.

Depressive Symptoms at T2 and T3. The Dimensions of Depression Profile for Children and Adolescents (DDPCA; [27]) contains 30 items assessing five depressive dimensions (mood, global self-worth, energy/interest, self-blame, and suicidal ideation), that have been identified as the essential defining features of depression [38, 27]. Scores were reversed so that higher scores represented increased depression. Discriminant validity is shown by correlations with items from 
the Childhood Depression Inventory [38] that tap the primary symptoms of depression (self-worth, energy/interest, and self-blame), but not the overall CDI score which taps a much broader range of behaviours and symptoms [27]. The DDPCA has been successful at identifying individuals at high risk of suicide [17, 28, 29].

Social Preference. We used sociometry to derive a popularity index for each child at T1 and T2. Each child is asked to pick children from their class photograph that they 'like most' and those they 'like least'. They were allowed to pick as many children from the class list as they liked and disliked so as to allow for the fact that some classes may be more sociable than others. To permit comparison of number of nominations across classrooms that varied in size and sociability, a proportion score is computed for each child, and the proportion score was standardised for each classroom. The difference between 'like most' and 'like least' standardised scores was computed and re-standardised as a measure of social preference. Higher scores indicate greater acceptance among peers, and lower scores indicate greater rejection [14]. Data from sociometric nominations are considered to be the most reliable and valid indices of acceptance and rejection among peers [14].

Loneliness at T1 and T2. We used the Peer and Parent subscales of the Loneliness and Aloneness Scale for Children and Adolescents (LACA [45]). There are 12 items for each of these two subscales. At T1, a revised version of the LACA [54] was used. This version includes pictures that depict each statement, which allow the interviewer to provide the child with a visual representation to refer to when making their rating about whether they never (1), sometimes (2), or always (3) feel this way. At T2, we used the standard LACA, without the T1 pictures to demonstrate each scenario, and a 4point rating scale, ranging from 1 (never) to 4 (often). Scores on each subscale could range from 1248, with higher scores indicating higher loneliness in that given domain. 
The LACA has high internal consistency and construct validity [25]. Test-retest reliability of the revised pictorial version of the questionnaire after 3 months is satisfactory, with high internal consistency [54].

T1-T2 Loneliness and Peer Acceptance/Rejection Duration. We hypothesised that enduring loneliness would affect depression independently of the additive effect of T1 and T2 loneliness. To model this interaction, duration scores for peer and parent loneliness and social preference scores were computed from the product of $\mathrm{T} 1$ and $\mathrm{T} 2$ scores. To reduce multicollinearity problems, $\mathrm{T} 1$ and T2 z-scores were used [3].

Analysis Plan

A Pearson correlation matrix was computed to assess univariate prediction of T3 depressive symptoms. Significant univariate predictors were entered into a Structural Equation Model (SEM) to examine structural links between T1 and T2 predictors and T3 depressive symptoms. T1 and T2 peer- and parent- related loneliness and social preference variables were used to directly predict depression. An independent effect of these is indicated by a significant path between T1 and/or T2 variables and depression. Direct effects of teacher ratings of internalising and externalising at T1, and T2 depressive symptoms scores were included to provide statistical control of pre-existing vulnerability to depression and depressive symptoms respectively. Social preference at T1 and T2 and duration (T1 x T2) are used as indicators of the latent variable peer acceptance, and again, are included as statistical control for pre-existing vulnerability to depression. The model also allows covariance between the following variables: T1 internalising, externalising and T1 peer loneliness. Also, direct links will be evident from T1 and T2 peer loneliness and the duration; T1 and T2 parent loneliness and duration; and T1 and T2 social preference and duration. 


\section{Results}

\section{Data Reduction}

The mood, energy, self-worth, self-blame and suicide subscales of the DDPCA measure at T2 and T3 were subjected to a principal components analysis. This yielded a “depressive symptoms” factor at each time point (eigen values: T1=2.25; T2: 2.21 ) that accounted for $57 \%$ and $55 \%$ of the variance respectively, with loadings of .82, .54, .85, .75, and .69 (T2) and .89, .52, .79, 65, and 74 (T3) for the five subscales, respectively. In both instances, energy had poor loadings. Thus, only the four subscales of mood, self-worth, self-blame and suicide were summed and used to create an overall 'depressive symptoms’ variable that is used in the initial correlational analyses. In the SEM, a latent variable for depressive symptoms at T3 was created using these four subscales as indicator variables.

Means and Correlations

Means, SDs and correlations among the measures for the full sample are shown in Table 1. The results show that internalization at $\mathrm{T} 1$, reports of depressive symptoms at $\mathrm{T} 2$, peer loneliness at $\mathrm{T} 2$, and parent loneliness at T1 positively predicted several reported depressive symptoms at T3. In addition, peer loneliness duration, and social preference duration also predicted T3 symptoms of depression.

Table 1 about here

All significant univariate predictors were included in the initial SEM, which showed a moderate fit of the data $\left(\chi^{2}[28]=87.59 p<.001 ; \mathrm{CFI}=.82\right.$, RMSEA $\left.=.09\right)$. We examined modification indexes and conducted Lagrange tests of significance to determine the addition of paths and the Wald test for 
the removal of paths. T1 parent loneliness and social preference duration were removed. These changes led to the final model specifications as detailed in Figure 1. The revised SEM fits the data well, $\left(\chi^{2}[3]=8.21 p<.04\right.$; CFI $=.98$, RMSEA $\left.=.07 .{ }^{1}\right)$.

The structural model showed independent prediction of higher T3 depressive symptoms by higher T2 reports of depressive symptoms, and duration of peer loneliness. T1 peer loneliness directly predicted T2 peer loneliness, and T1 internalisation predicted T2 depressive symptoms. T1 and T2 loneliness, parent loneliness (T1, T2, and duration), social preference (at T1, T2 and duration), and externalization did not independently predict T3 depression.

Figure 1 about here

The observed effect of duration of peer loneliness found in the SEM was further explored by examining the slopes of the relation between peer loneliness at T1 and depression for different levels of the moderator: peer loneliness at T2. The three levels are: 1 SD above the mean (high peer loneliness at T2), the mean (medium peer loneliness at T2) and 1 SD below the mean (low peer loneliness at T2). Depression at T3 increased as a function of peer loneliness at T1 for high peer loneliness at T2 $(\beta=.77, p<.005)$ and for medium peer loneliness at T2 $(\beta=.54, p<.05)$ but not for low peer loneliness at T2 $(\beta=.12)$. As shown by the slopes in Figure 2, participants who had high peer loneliness at T1 and high peer loneliness at T2 showed the maximum level of depression whereas other combinations of peer loneliness at T1 and T2 were associated with low levels of depression. The findings show that those children who were consistently high in peer loneliness across time (i.e. those children who reported non-transient feelings of loneliness) were later likely to report depressed feelings. ${ }^{2}$ 
Figure 2 about here

\section{Discussion}

The present study is the first to examine the predictive effects of childhood loneliness on depressive symptoms during adolescence. By using an eight-year prospective design with a large number of participants, we have established a sequential link between childhood loneliness and symptoms of depression in adolescence. Controlling early indicators of vulnerability and reports of depressive symptomology, we found that the stability of childhood loneliness predicted later adolescent reports of depressive symptoms. This finding provides support for the notion that loneliness as an enduring pattern over a four year period is linked to symptoms of depression.

We suggest that enduring loneliness represents an interpersonal stressor that plays a causal role in the development of later symptoms of depression. However, we did not investigate the mediators of this effect in this study. Animal and human studies suggest that the experience of early adversity can have a long lasting impact on reactivity to future stresses via changes in the hypothalamic-pituitaryadrenal (HPA) axis [7, 30]. Also, loneliness may cause children to develop maladaptive cognitive biases and coping strategies that predispose them to depression [54, 55]. Depressogenic cognitions have been shown in young children [47], and it is possible that these are augmented by loneliness. Still further, it may be the case that people who experience stable loneliness have a deficit in the appreciation of relationships [22]: caused by changes in activation and functioning of the HPA axis [11] as a learned response from early stressful attachment relationships or a genetic predisposition 
that sets the lonely person's standards for social engagement very high [30]. Such a deficiency may work alongside the dysfunctional cognitions.

An alternative explanation is that enduring loneliness is part of a pattern of sequential comorbidity with depression, representing an age-dependent expression of the same underlying disorder. However, we controlled for early indicators of depression psychopathology using two early indicators of vulnerability to depression, and self reports of depressive symptoms, and found that non-transient peer related loneliness was predictive of later adolescent depressive symptoms. One wonders why this might affect only peer loneliness. Our findings suggest that, similar to the cross-sectional literature [41], peer loneliness is a more potent prospective risk factor for depression than dissatisfaction with parental relationships. To some extent, this can be explained by the substantial interpersonal transitions that also occur at the developmental level under investigation [59]. The critical developmental period between early-middle childhood and adolescence is characterised by significant increases in the frequency and influence of contacts with peers, with peers generally becoming more important than the family, demanding more from children by way of resources and social skill.

This study is not without its limitations. First, due to the age of the sample, we were not able to directly measure depression at T1; instead, we used teacher ratings of internalising and externalising behaviour. These measures were not strong predictors of T2 depression (Table 1), suggesting that they may not be optimal control variables. However, we believe that the T1 observations provide new and valuable insights into the development of adolescent depression, but we must also caution readers that T1 depression may not have been optimally measured and, thus, not fully controlled. More accurate measurement of depressive symptoms in young children is an important direction for future research. 
There are also alternative sequential models that have not been tested. For example, an alternative interpretation implies that loneliness and depression are independent but sequential manifestations of an unmeasured maladaptive process [54]. Another possible model is that internalizing problems in young children cause peer rejection and loneliness in later childhood, which then leads to depression in adolescence [51]. Given the lack of any associations between peer rejection and loneliness (T1 and T2) or depression (T3) in the current study, such an explanation does not fit the current data. Nevertheless, it will be important to compare such models in future work.

These findings suggest other clear directions for future research. First, the role of potential mediators, such as HPA activation and depressive cognitions about social relationships, could be explored to develop theoretically-based explanations of how childhood loneliness may cause later depressive symptomology. Second, enduring loneliness may interact with other stressors, such as parental separation or illness to cause depression. Subsequent research would also be aimed at detecting moderators of this relationship. These may involve protective factors inherent in the child's temperament or in the child's immediate environment, such as family social support mechanisms and social economic background [11], or structured intervention programmes designed to help children to establish more satisfying relationships.

These findings emphasise the need to consider policy-level intervention to develop screening programmes that provide children with the cognitive and social skills to negotiate satisfying relationships and to intervene with individual children experiencing prolonged feelings of loneliness. It follows from this work that alleviation of loneliness in childhood may provide a protective factor against depression amongst adolescents and adults, but to date no empirical evidence exists that demonstrates the usefulness of specific interventions for lonely children [56]. 
This study has established prospective links between loneliness and depression over an eight year period from early/middle childhood to adolescence. Further research is required to better understand processes by which this occurs. In particular, we have suggested that HPA changes or depressogenic cognitive biases may play a role, but it is unclear whether these are caused by experiences of loneliness, exist prior to them, or interact with other variables to predispose children to later depression.

\section{Acknowledgements}

Thanks are extended to Anna Kearney and Peter Fleming for assisting with data collection and input. Thanks also to Lancashire County Council for their help in tracking the children and forwarding consent forms to parents. Also, many thanks to the teachers and children who took part in the study. In addition, we would like to thank the two anonymous reviewers for their comments and recommendations. 


\section{References}

1. Abramson LY, Alloy LB, Hankin BL, Haeffel GJ, MacCoon DG, Gill BE (2002) Cognitivevulnerability-stress models of depression in a self-regulatory and psychological context. In: Gotlib IH, Hammen EL (eds) Handbook of depression. Guilford, New York

2. Adams, J., White, M. (2006). Removing the health domain from the Index of Multiple Deprivation - effect on measured inequalities in census measure of health. Journal of Public Health 28: 379-383.

3. Aiken LS, West SG (1991) Multiple Regression: Testing and Interpreting Interactions. Sage, Newbury Park, CA

4. Birmaher B, Ryan SW, Williamson D, Brent D, Kaufman J, Dahl R, Perel J, Nelson B (1996) Childhood and adolescent depression: A review of the past ten years. Journal of the American Academy of Child and Adolescent Psychiatry 35: 1427-1439

5. Boivin M, Hymel S, Bukowski WM (1995) The roles of social withdrawal, peer rejection, and victimisation by peers in predicting loneliness and depressed mood in childhood. Development and Psychopathology 7:765-785

6. Borelli JL, Prinstein MJ (2006) Reciprocal, longitudinal associations among adolescents’ negative feedback-seeking, depressive symptoms, and peer relations. Journal of Abnormal Child Psychology 34:159-169

7. Boyce WT, Ellis BJ (2005) Biological sensitivity to context: An Evolutionary-developmental theory of the origins ad functions of stress reactivity. Developmental Psychopathology 17:271-301 
8. Brendgen M, Wanner B, Morin AJS, Vitaro F (2005) Relations with parents and with peers, temperament, and trajectories of depressed mood during early adolescence. Journal of Abnormal Child Psychology 33:579-594

9. Buhs ES, Ladd GW (2001) Peer rejection as antecedent of young children's school adjustment: An examination of mediating processes. Developmental Psychology 37:550-560

10. Cacioppo JT, Hughes ME, Waite LJ, Hawkley LC, Thisted RA (2006) Loneliness as a specific risk factor for depressive symptoms: Cross sectional and longitudinal analyses. Psychology and Ageing 21:140-151

11. Cacioppo JT, Patrick W (2008) Loneliness: Human Nature and the Need for Social Connection. W.W. Norton and Company, London.

12. Carstensen LL, Isaacowitz DM, Charles ST (1999) Taking time seriously: A theory of socioemotional selectivity. American Psychologist 54:165-181

13. Cohen J, Cohen P, West SG, Aiken LS (2002) Applied Multiple Regression/Correlation Analysis for the Behavioural Sciences. Lawrence Erlbaum Associates, London.

14. Coie JD, Dodge K A (1983) Continuity of children's social status: A five-year longitudinal study. Merrill-Palmer Quarterly 29:261-282

15. Connors, C (1969) A teacher rating scale for use in drug studies with children. American Journal of Psychiatry 126:884-888

16. Cowen E, Gesten EL, Wilson AB (1979) The primary mental health project (PMHP): Evaluation of current program effectiveness. American Journal of Community Psychology 7:293-303 17. Crocker AD, Hakim-Larson J (1997) Predictors of pre-adolescent depression and suicidal ideation Canadian Journal of Behavioural Science 29:76-82 
18. Dumas JE, Neese DE, Prinz RJ, Blechman EA (1996) Short term stability of aggression, peer rejection, and depressive symptoms in middle childhood. Journal of Abnormal Child Psychology 24:105-119

19. Eberhart NK, Hammen CL (2006) Interpersonal predictors of onset of depression during the transition to adulthood. Personal Relationships 13:195-206

20. Ferguson DM, Horwood LJ, Ridder EM, Beautrais AL (2005) Subthreshold depression in adolescence and mental health outcomes in adulthood. Archives of General Psychiatry 62:66-72 21. Ferguson DM, Woodward LJ (2002) Mental health, educational, and social role outcomes of adolescents with depression. Archives of General Psychiatry 59:225-231

22. Flora J, Segrin C (2000) Relationship development in dating couples: Implications for relational satisfaction and loneliness. Journal of Social and Personal Relationships 17:811 - 825

23. Fombonne E, Wostear G, Cooper V, Harrington R, Rutter M (2001) The Maudsley long-term follow-up of child and adolescent depression. British Journal of Psychiatry 179:210-217

24. Gerson A, Perlman D (1979) Loneliness and expressive communication. Journal of Abnormal Psychology 88:258-261

25. Goossens L, Beyers W (2002) Comparing measures of childhood loneliness: Internal consistency and confirmatory factor analysis. Journal of Clinical Child Psychology 31:252-262

26. Hagerty BM, Williams RA (1999) The effects of sense of belonging, social support, conflict, and loneliness on depression. Nursing Research 48:215-219

27. Harter S, Nowakowski M (1987) Manual for the dimensions of depression profile for children and adolescents. University of Denver.

28. Harter S, Marold DB (1994) Psychosocial risk factors contributing to adolescent suicidal ideation. New Directions in Child Development: 71-91 
29. Harter S, Marold D, Whitesell NR (1992) A model of psychosocial risk factors leading to suicidal ideation in young adolescents. Development and Psychopathology 4:167-188 30. Hawkley LC, Cacioppo JT (2003) Loneliness and pathways to disease. Brain, Behaviour, and Immunity 17:S98-S105

31. Heikkinen R, Kauppinen M (2004) Depressive symptoms in late life: A 10 year follow-up. Archives of Gerontology and Geriatrics 38:239-250

32. Henin A, Biederman J, Mick E, Sachs GS, Hirshfield-Becker DR, Siegel RS, McMurrich S, Grandin L, Nierenberg AA (2005) Psychopathology in the offspring of parents with bipolar disorders: A controlled study. Biological Psychiatry 58:554-561

33. Hymel S, Tarulli D, Hayden-Thomson L, Terrell-Deutsch B (1999) Loneliness through the eyes of children. In: Rotenberg KJ, Hymel, S (eds) Loneliness in childhood and adolescence. Cambridge University Press, Cambridge.

34. Kerr DCR, Preuss LJ, King CA (2006) Suicidal adolescents’ social support from family and peers: Gender-specific associations with psychopathology. Journal of Abnormal Child Psychology 34:103-114

35. Kistner J, Balthazor M, Risi S, Burton C. (1999). Predicting dysphoria in adolescence from actual and perceived peer acceptance in childhood. Journal of Clinical Child Psychology 28:94-104 36. Koenig LJ, Abrams RF (1999) Adolescent loneliness and adjustment: A focus on gender differences. In: Rotenberg KJ, Hymel, S (eds) Loneliness in childhood and adolescence. Cambridge University Press, Cambridge.

37. Koenig LJ, Isaacs AM, Schwartz JAJ (1994) Sex differences in adolescent depression and loneliness: why are boys lonelier if girls are more depressed? Journal of Research in Personality 28:27-43. 
38. Kovacs M (1985) The Children's Depression, Inventory (CDI). Psychopharmacology Bulletin 21:995-998

39. Kupersmidt JB, Patterson CJ (1991) Childhood peer rejection, aggression, withdrawal, and perceived competence as predictors of self-reported behaviour problems in preadolescence. Journal of Abnormal Child Psychology 19:427-449

40. Ladd GW (2006) Peer rejection, aggressive or withdrawn behaviour, and psychological maladjustment from ages 5-12: An examination of four predictive models. Child Development $77: 822-846$

41. Lau S, Chan DWK, Lau PS (1999) Facets of loneliness and depression among Chinese children and adolescents. The Journal of Social Psychology 139:713-729.

42. Leve LD, Kim HK, Pears KC (2005) Childhood temperament and family environments as predictors of internalising and externalising trajectories from ages 5 to 17. Journal of Abnormal Child Psychology 33:505-520

43. Lorion RP, Cowen EL (1978) Referral to school mental health project: a screening note. American Journal of Community Psychology 6:247-51

44. Luby JL, Heffelfinger A, Koenig-McNaught AL, Brown K, Spitznagel E (2004) The preschool feelings checklist: A brief and sensitive screening measure for depression in young children. Journal of the American Academy of Child and Adolescent Psychiatry 43:708-717

45. Marcoen A, Goossens L, Caes P (1987) Loneliness in pre through late adolescence: Exploring the contribution of a multidimensional approach. Journal of Youth and Adolescence 16:561-577 46. Martin JM, Cole DA, Clausen C, Logan J, Wilson Strosher HL (2003) Moderators of the relation between popularity and depressive symptoms in children: processing strength and friendship value. Journal of Abnormal Child Psychology 31:471-483 
47. Murry L, Woolgar M, Cooper P, Hipwell A (2001) Cognitive vulnerability to depression in 5year old children and depressed mothers. Journal of Child Psychology and Psychiatry 42:891-899 48. Nangle DW, Erdley CA, Newman JE, Mason CA, Carpenter EM (2003) Popularity, friendship quantity, and friendship quality: Interactive influences on children’s loneliness and depression. Journal of Clinical Child and Adolescent Psychology 32:546-555

49. Nolen-Hoesksema S, Ahrens C (2002) Age differences and similarities in the correlates of depressive symptoms. Psychology and Ageing 17:116-124

50. Panak WF, Garber J (1992) Role of aggression, rejection, and attributions in the prediction of depression in children. Development and Psychopathology 4:145-165

51. Pederson, S., Vitaro, F., Barker, E.D., \& Borge, A.I.H. (2007). The timing of middle-childhood peer rejection and friendship: Linking earl behaviour to early adolescent adjustment. Child Development 78: 1037-1051.

52. Peplau LA, Perlman D (1982) Perspectives on loneliness. In: Peplau, LA, Perlman., D (eds), Loneliness: A sourcebook of current theory, research and therapy. Wiley-Interscience, New York. 53. Prinstein MJ, Aikins JW (2004) Cognitive moderators of the longitudinal association between peer rejection and adolescent depressive symptoms. Journal of Abnormal Child Psychology 32:147158

54. Qualter P, Munn P (2002) The separateness of emotional and social isolation in childhood. Journal of Child Psychology and Psychiatry 43:233-244

55. Qualter P, Munn, P (2005) The friendships and play partners of lonely children. Journal of Social and Personal Relationships 22:379-397

56. Qualter, P. (2003). Loneliness in children and adolescents: What do schools and teachers need to know and how can they help? Pastoral Care in Education 21: 10-19. 
57. Renshaw PD, Brown PJ (1993) Loneliness in middle childhood: concurrent and longitudinal predictors. Child Development 64:1271-1284

58. Rotenberg K J (1999). Childhood loneliness: An introduction. In: Rotenberg KJ,\& Hymel S (eds.) Loneliness in childhood and adolescence. Cambridge University Press, Cambridge.

59. Rudolph KD, Hammen C, Burge D, Lindberg N, Herzberg D, Daley SE (2000) Toward an interpersonal life-stress model of depression: The developmental context of stress generation. Development and Psychopathology 12:215-234

60. Rutter M, Kim-Cohen J, Maughan B (2006) Continuities and discontinuities in psychopathology between childhood and adult life. Journal of Child Psychology and Psychiatry 47:276-295

61. Sund AM, Larsson B, Wichstrom L (2003) Psychosocial correlates of depressive symptoms among 12-14 year old Norwegian adolescents. Journal of Child Psychology and Psychiatry and Allied Disciplines 44:588-597

62. Tabachnick BG, Fidell LS (2001) Using multivariate statistics (4 ${ }^{\text {th }}$ ed.) Allyn \& Bacon, Boston. 63. Valery JH, O'Connor P, Jennings S (1997) The Nature and Amount of Support College-Age Adolescents Request and Receive from Parents. Adolescence 32:323-337

64.Weissberg RP, Cowen EL, Lotyczewski BS, Gesten EL (1983) The Primary Mental Health Project: Seven consecutive years of program outcome research. Journal of Consulting and Clinical Psychology 51:100-107

65 Young JE (1982) Loneliness, depression, and cognitive therapy: Theory and application. In: Peplau LA, Perlman D (eds). Loneliness: A sourcebook of current theory, research, and therapy. Wiley, London 
Table 1: Variable Means, SDs and Intercorrelations

\begin{tabular}{|c|c|c|c|c|c|c|c|c|c|c|c|c|c|c|}
\hline & Mean & $S D$ & 2 & 3 & 4 & 5 & 6 & 7 & 8 & 9 & 10 & 11 & 12 & 13 \\
\hline 1. T1 Peer Lonely & 13.40 & 6.54 & $.38 * *$ & .09 & .05 & .07 & .15 & -.04 & -.02 & .04 & $.32 * *$ & .18 & .07 & .06 \\
\hline 2. T2 Peer Lonely & 26.91 & 6.21 & & .01 & $.12^{*}$ & $.16^{* *}$ & $.17^{*}$ & .01 & -.04 & .04 & $.24 * *$ & .04 & $.13^{*}$ & $.12^{*}$ \\
\hline 3. T1xT2 Peer Lonely Duration & .76 & 1.67 & & & .02 & .01 & $.15^{*}$ & .03 & .04 & $-.17 *$ & $.83^{* *}$ & $.68^{* *}$ & $.58^{* *}$ & $.69 * *$ \\
\hline 4. T1 Parent Lonely & 3.09 & 2.23 & & & & $.18 * *$ & $.13^{*}$ & $.21 * *$ & .02 & $.19 * *$ & .09 & .02 & $.19 * *$ & $.13^{*}$ \\
\hline 5. T2 Parent Lonely & 15.26 & 6.22 & & & & & & -.08 & $.13 *$ & .01 & -.07 & $.15^{*}$ & $.12 *$ & .08 \\
\hline 6. T1xT2 Parent Lonely Durati & .17 & 1.29 & & & & & & .02 & -.03 & .03 & $.14^{*}$ & .07 & -.11 & .08 \\
\hline 7. T1 Social Preference & -.07 & 1.38 & & & & & & & $.45^{* *}$ & $.34 * *$ & .07 & $.18^{* *}$ & .06 & .04 \\
\hline 8. T2 Social Preference & .05 & 1.25 & & & & & & & & $.33 * *$ & -.05 & .09 & .02 & .06 \\
\hline 9. T1xT2 Social Pref. Duration & .70 & 1.94 & & & & & & & & & $.20 * *$ & .07 & .09 & $.14^{*}$ \\
\hline 10.T1 Internalisation & 5.36 & 3.96 & & & & & & & & & & .10 & $.19 * *$ & $.24^{* *}$ \\
\hline 11.T1 Externalisation & 6.67 & 4.63 & & & & & & & & & & & .08 & .03 \\
\hline 12.Depressive symptoms $\mathrm{T} 2^{\alpha}$ & 11.78 & 4.14 & & & & & & & & & & & & $.59 * *$ \\
\hline 13 .Depressive symptoms $\mathrm{T}^{\alpha}$ & 13.10 & 4.44 & & & & & & & & & & & & $----\cdot$ \\
\hline
\end{tabular}

$\alpha$ Variable is the sum of four subscales (mood, self-worth, self-blame and suicide) of the DDPCA based on earlier principal components analysis. 
Figure Captions

Figure 1: Full Structural Equation Model

Figure 2: Slopes of the Relation between Depression at T3 and Peer Loneliness at T1 as a Function of Levels of Peer Loneliness at T2

Figure 1: Final model linking control and loneliness variables to later depressive symptoms

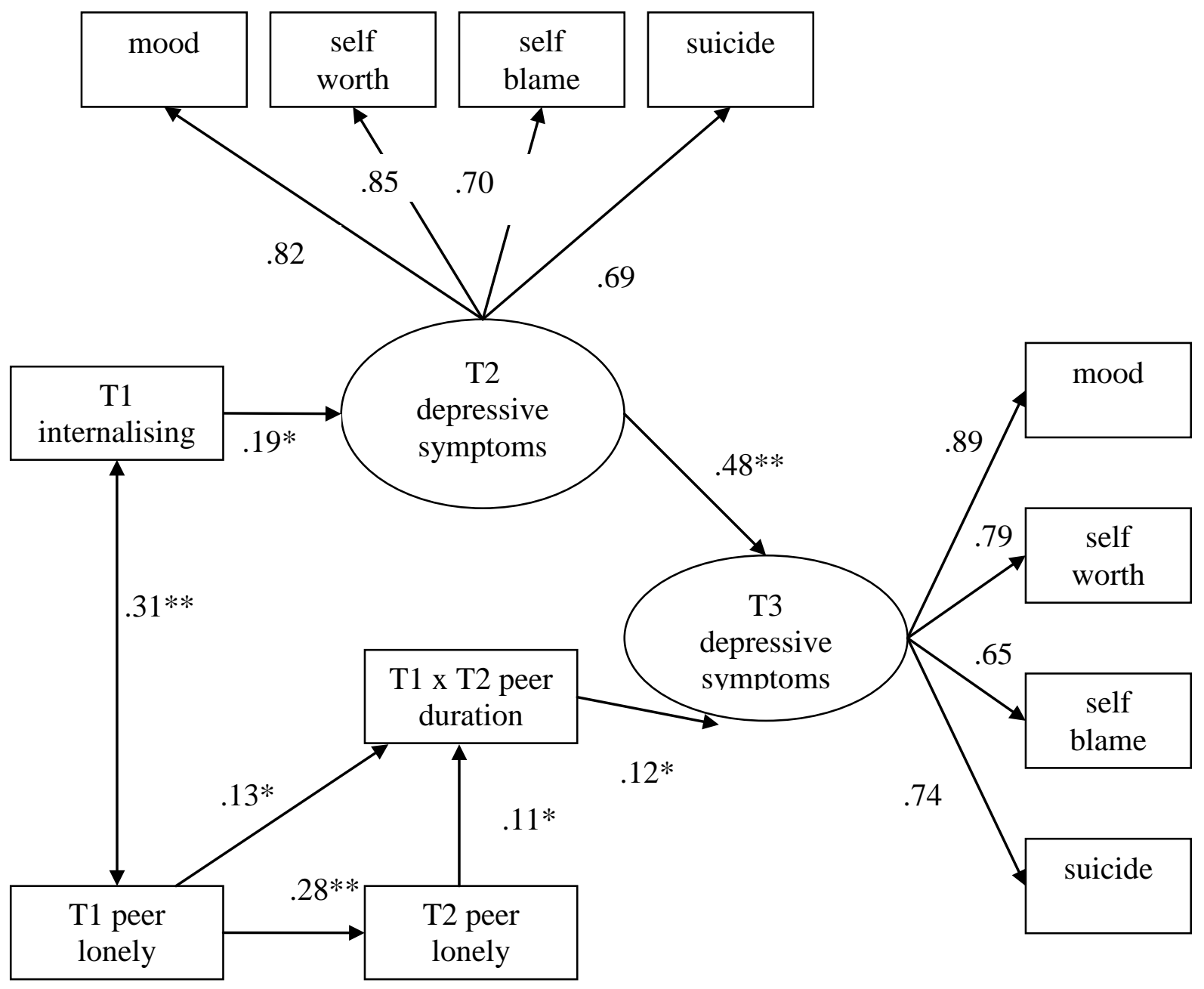


Figure 2: Slopes of the Relation between Depressive symptoms at T3 and Peer Loneliness at T1 as a Function of Levels of Peer Loneliness at T2

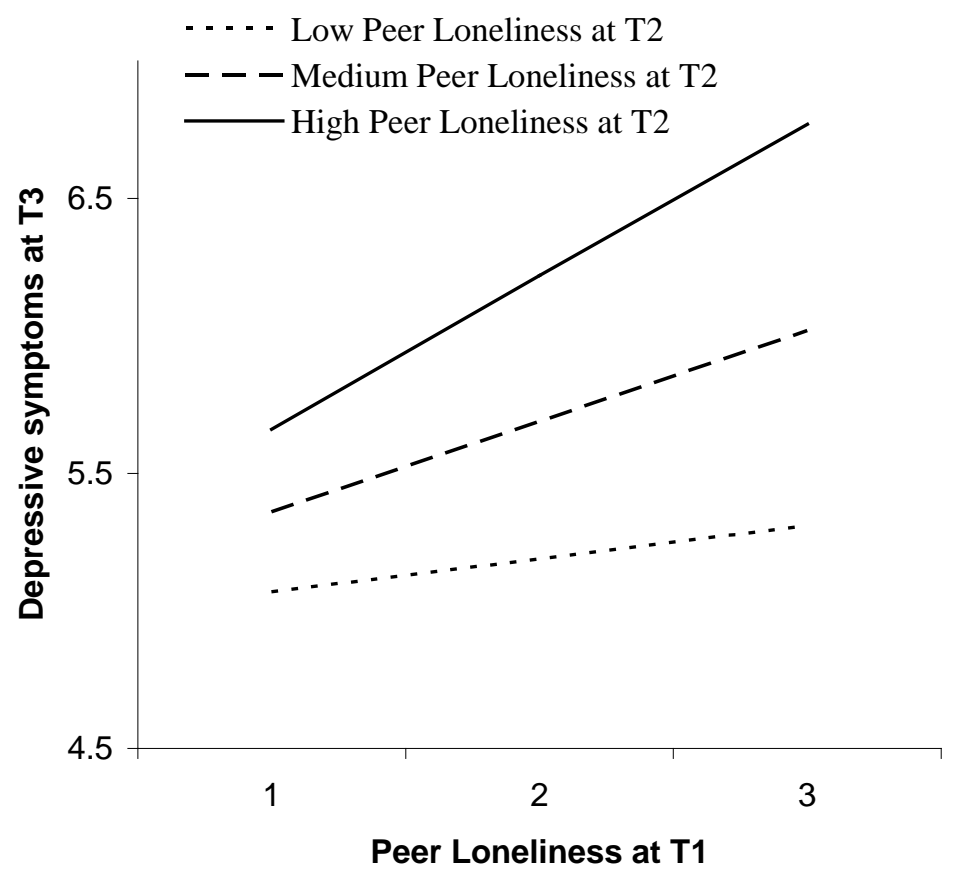

